\title{
Detection of bacterial wilt disease (Pseudomonas solancearum) in Brinjal using hyperspectral remote sensing
}

\author{
Aditi Srivastava*, Shreya Roy, M. M. Kimothi, P.Kumar, Seema Sehgal, S. Mamatha and S. S. Ray \\ Mahalanobis National Crop Forecast Centre, DAC\&FW, New Delhi -110 012 (jeejivisha, royshreya406, drmmkimothi, \\ pradeeprose94, seemasehga193, mamata.sanapala, shibendu.ray)@gmail.com
}

\section{Commission III, WG III/10}

KEYWORDS: Hyperspectral, Bacterial wilt disease, Chlorophyll, Leaf Area Index, Spectroradiometer

\begin{abstract}
:
Bacterial wilt disease (pathogen: Pseudomonas solancearum) is a major problem affecting brinjal crop. Infected leaves show yellowing, loss in turgidity, drying and ultimately the entire plant collapses. The study aims to examine the potential of hyperspectral remote sensing for detection of biotic stress caused due to bacterial wilt disease and identify best spectral band widths and hyperspectral indices indicative of disease infestation. This study was conducted in a farmer's plot at Alampur in Baruipur block, South 24 Pargana district, West Bengal. Canopy spectra (using ASD Fieldspec 2 Spectroradiometer), chlorophyll content (by Chlorophyll meter) and Leaf Area Index (LAI) (by plant canopy imager) were collected. The healthy plants had green and fully turgid leaves whereas diseased plants had lower chlorophyll content and LAI. The reduction in chlorophyll content lowered reflectance in green region and internal leaf damage in near-infrared region. A correlation analysis was carried out between reflectance at specific bandwidths and hyperspectral indices with chlorophyll content and LAI of healthy and stressed plants. Bandwidths of 528-531 nm, 550-570 nm, 710-760 nm, and single bands such as $800 \mathrm{~nm}$ and $920 \mathrm{~nm}$ and indices viz. Greenness index, Modified Chlorophyll Absorption in Reflectance Index (MCARI), Transformed Chlorophyll Absorption in Reflectance Index (TCARI), Triangular Vegetation Index (TVI), Simple Ratio Pigment Index (SRPI), Photochemical Reflectance Index (PRI 2), Lichtenthaler Indices (LIC1, LIC2), Structure Intensive Pigment Index (SIPI) etc. were found to have strong positive correlation $\left(\mathrm{R}^{2}>0.9\right)$ with plant parameters. These specific bandwidths and indices can be helpful in biophysical parameter estimation and early detection of crop stress, crop growth and disease monitoring.
\end{abstract}

\section{INTRODUCTION}

Brinjal (Solanum melongena) or eggplant is considered as one of the important vegetable crops after potato,onion and tomato. According to an estimate, in India, about 1.4 million small and marginal farmers grow brinjal crop for a regular and steady income (Choudhary et al., 2009). West Bengal state of India has the highest area (about 160 thousand hectares) under Brinjal cultivation in India with a production of approximately 3000 thousand tonnes. The major brinjal producing belts in the state are South 24-Paraganas, Cooch Behar, Jalpaiguri, Nadia, Murshidabad and Malda. Bacterial wilt disease (pathogen: Pseudomonas solancearum) has been widely reported for causing severe problems in brinjal cultivation in the tropical, sub tropical and warm temperate regions of the world.

Several researchers have reported the occurrence of this devastating disease from India, and especially, West Bengal (Das et al., 1955; Chatterjee et al., 1997; Samaddar et al., 1998; Mondal el al., 2004b). It has been reported that brinjal crops transplanted during summer months are more prone to get infected with this disease (Mondal et al., 2014). Wilting is generally observed in the reproductive stage of the crop growth, caused by infection in the vascular system of the plant. The pathogen enters the water-conducting xylem vessels of a plant, then proliferates within the vessels, causing water blockage. Infected leaves show yellowing, loss in turgidity, drying and ultimately the entire plant collapses.

*Corresponding Author
Several attempts have been made in developing techniques for crop visual monitoring and quantification of stress induced by pathogenic diseases. Several authers (Thomas et al., 1972; Toler et al., 1981; Blazquez et al., 1983; Kurschner et al., 1984; Blakeman, 1990) have reported that the spectral reflectance of green vegetation in the red band $(0.6-0.7 \mu \mathrm{m})$ is most sensitive to leaf chlorophyll and pigment contents while the near infrared (NIR) band $(0.7-0.9 \mu \mathrm{m})$ is most sensitive to biomass and leaf area index. It has been observed that the stressed plants have lower absorption of red light and higher absorption of NIR radiation (Lillesand and Kiefer, 1994; Guyot, 1990; Hatfield et al., 1993). These spectral characteristics of green plants can be used to evaluate the stresses of various crops (Chapelle et al., 1992; Shibayama et al., 1993; Zhang et al., 2002; Fitzgerald et al., 2004).

Empirical relationships can be established between the factors that cause plant stress and the variations observed in the resulting reflectance signatures (Jacquemoud et al., 2001). Many researchers have examined vegetation pigment levels using reflectance data at specific wavelengths or by creating ratios of reflectance data values at several specific wavelengths (Gitelson et al., 2006; Gitelson et al., 2002; Blackburn, 1998a; Blackburn, 1998b; Serrano et al., 2002; Haboudane et al., 2008) or at the red-edge (Jones et al., 2010). Zhang et al. (2002) demonstrated the ability to distinguish healthy tomato plants from late blight infected plants using PCA, cluster analysis, and spectral ratio analysis in several fields of tomatoes with varying levels of infection. Kumar et al. (2010) reported that spectral indices like Normalized Difference Vegetation Index (NDVI), 
Ratio Vegetation Index (RVI), Aphid Index (AI) and Structure Insensitive Pigment Index (SIPI) had significant correlation with aphid infestation in mustard crop. Ray et al. (2011) investigated the utility of hyperspectral reflectance data for potato late blight disease detection. The differences between the vegetation indices for plants at different levels of disease infestation were found to be highly significant. The optimal hyperspectral wavebands to discriminate the healthy from disease infested plants were 540, 610, 620, 700, 710, 730, 780 and $1040 \mathrm{~nm}$, whereas up to $25 \%$ infestation could be discriminated using reflectance at 710,720 and $750 \mathrm{~nm}$. Though, it is difficult to visually quantify the nature of stress, these responses affect the amount and quality of electromagnetic radiation reflected from plant canopies (Sahoo et al., 2015). Spectral reflectance data provides a means for detection of disease infestation to help reduce potential production losses, restrain environmental risk, and decrease the cost of farming. Irrespective of whether or not high value crops are infected with a disease, growers typically apply pesticides as insurance to diminish the risk of losing large amounts of their crop. Agricultural producers spray chemicals uniformly over entire fields to prevent or control disease, which is unnecessarily costly since disease infestation is predominately concentrated in patches around original foci where disease originates (Moshou et al., 2004), with large areas of fields free from disease at any stage of infestation (Bravo et al., 2003). In addition to higher production costs, repeated application of pesticides increases the risk of pests adapting to the pesticides, rendering the pesticides virtually ineffective. Excessive pesticide application may also increase the amount of toxic residues contaminating ground water, making targeted pesticide placement at the correct time an important goal. To prevent overuse of chemicals, growers need a remote sensing system that can provide timely detection of diseases (Zhang et al., 2005).

In this backdrop, this study aims to examine the potential of hyperspectral remote sensing for detection of biotic stress caused due to bacterial wilt disease and identify the best spectral band widths and hyperspectral indices indicative of disease infestation.

\section{METHODOLOGY}

\subsection{Study Area}

This study was conducted in Brinjal growing fields of farmers in Alampur at Baruipur block of South 24 Pargana district, West Bengal (Figure 1). The district of south-24 Parganas encompasses the moribund, mature as well as active parts of the Ganga delta, bounded by the great Sunderbans mangrove forest at its south-western side. The Baruipur block is located in the northern inland tracts of the district. Its land surface is flat with an elevation of only 3-5 m above mean sea level and the soils are mainly alluvial in nature and predominantly clay loam, hence very favourable for agriculture. The normal annual rainfall in this district is of the tune of $1800 \mathrm{~mm}$. The district is characterized by hot and humid climate. It receives adequate rainfall from North-East and South-West monsoons which set in the later half of June and withdraw by the middle of October. Pre-monsoon rains are received during March-April. May is the hottest month with temperature as high as $40^{\circ} \mathrm{C}$ and and January is the coldest month with temperature as low as $10^{\circ} \mathrm{C}$.

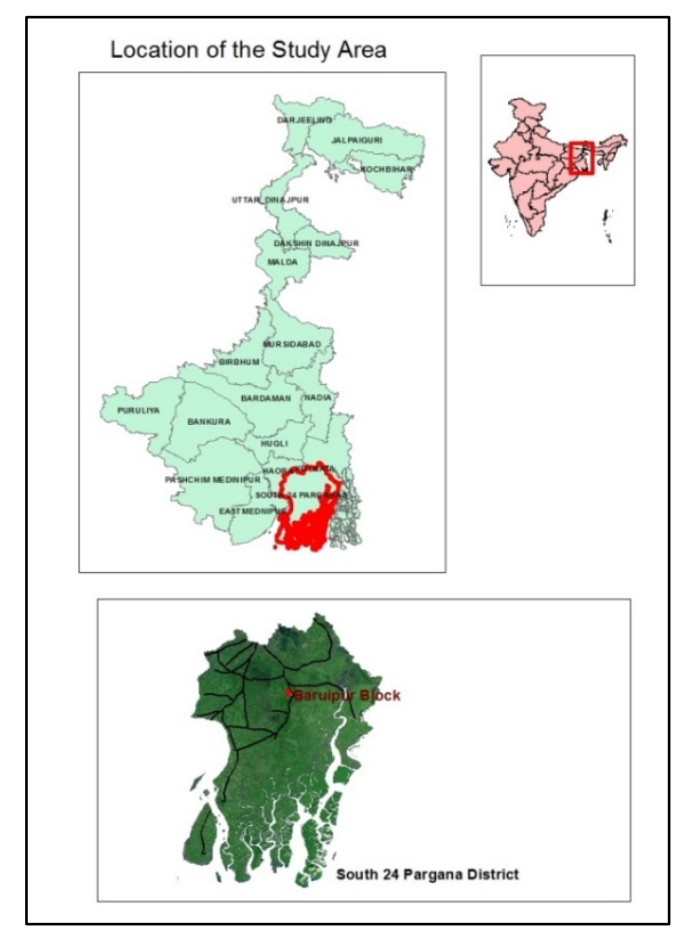

Figure 1. Study Area

\subsection{Data Collection}

\subsubsection{Hyperspectral Data:}

Hyperspectral reflectance data of healthy and diseased brinjal were collected, using ASD Fieldspec Handheld 2 Spectroradiometer. Data was captured between 11:00 am and 1:00 pm to maximize sunlight. Gathering spectra at a given location involves optimizing integration time (typically set at 17 $\mathrm{ms}$ ), providing foreoptic information, recording dark current, collecting white reference reflectance and obtaining the target reflectance. The target reflectance is the ratio of energy reflected off the target (eg. crop) to energy incident on the target (measured using BaSO4 white reference plate called Spectralon). Since the dark current varies with time and temperature, it was gathered for each integration time (virtually new for each plot). Reflectance measurements were made about one meter above the crop canopy with the sensor facing the crop and oriented normal to the plant using $25^{\circ}$ FOV (ASD Inc, 2010).

Hyperspectral Data Preprocessing: A window based software, View Spec Pro was used for viewing, analyzing and exporting the spectral data into ASCII format. The continguous spectral profile contained reflectance data in the spectral range of 325 to $1075 \mathrm{~nm}$ with $1 \mathrm{~nm}$ interval. Earlier studies (Apan et al., 2005) have shown that bands in close proximity has redundant information and there is high levels of noise between 350 to $400 \mathrm{~nm}$ It was found that keeping a bandwidth of 5-10 $\mathrm{nm}$ is optimum for crop stress studies (Ray et al., 2006). The spectral data was preprocessed accordingly at a bandwidth of 10 $\mathrm{nm}$ in the VNIR (400 to $1075 \mathrm{~nm}$ ) spectrum.

\subsubsection{Biophysical Data :}

Chlorophyll content in the leaves of healthy and diseased Brinjal plants were sampled using the instrument, Chlorophyll meter (MC-100). The instrument gives chlorophyll 
concentration reading i.e. CCI, by calculating the ratio of transmittance at $931 \mathrm{~nm}$ to transmittance at $653 \mathrm{~nm}$. A CCI measurement near 1 indicates similar transmittance of red and NIR radiation, thus little to no chlorophyll in the leaf sample. A CCI measurement greater than one indicates less transmittance of red radiation relative to near infra-red radiation (Apogee Instruments Inc, 2013). Leaf Area Index (LAI) data was collected using plant canopy imager Model No CI-110. Its value ranges from $0-10$, with 0 representing no canopy or bare ground and 10 representing a dense conifer forest canopy (CID Bioscience Inc, 2014).

\subsubsection{Ancillary Data :}

Crop condition and management practices followed at the site, were recorded using the ground truth performas. Geo-tagged field photographs was collected using android based smart phone (Asus Zenphone 2).

\subsection{Computation of Narrow Band Indices}

Different vegetation indices were computed which includes structural indices: NDVI; Chlorophyll indices: Greenness Index, MCARI (Modified Chlorophyll Absorption Reflectance Index), TCARI (Transformed Chlorophyll Absorption Reflectance Index),TVI (Triangular Vegetation Index), SIPI (Structural Insensitive Pigment Index), Normalized Phaeophytinization Index (NPQI), NPCI (Normalized Pigment Chlorophyll Index), PRI (Photochemical Reflectance Index), SRPI(Simple Ratio Pigment Index), Carter Indices, Lichtenthaler Indices and Red edge indices: Vogelmann Indices, ZTM (Zarco Tejada and Miller),GM1 and GM2. Details are given in Table 1.

\begin{tabular}{|c|c|c|}
\hline Index & Formula & Source \\
\hline Greeness index $(\mathrm{G})$ & R554/R677 & - \\
\hline $\begin{array}{lll}\text { Modified Chlorophyll absorption } & \text { in } \\
\text { Reflectance Index (MCARI) } & & \\
\end{array}$ & $((\mathrm{R} 700-\mathrm{R} 670)-0.2 *(\mathrm{R} 700-\mathrm{R} 550)) *(\mathrm{R} 700 / \mathrm{R} 670)$ & Daughtery et al. (2000) \\
\hline Transformed CARI (TCARI) & $\begin{array}{l}3 *((\mathrm{R} 700-\mathrm{R} 670)-0.2 *(\mathrm{R} 700- \\
\mathrm{R} 550) *(\mathrm{R} 700 / \mathrm{R} 670))\end{array}$ & Haboudane et al. (2002) \\
\hline Triangular Vegetation Index (TVI) & $0.5 *(120 *(\mathrm{R} 750-\mathrm{R} 550)-200 *(\mathrm{R} 670-\mathrm{R} 550))$ & Broge and Leblane (2000) \\
\hline Zarco-Tejada \& Miller (ZM) & R750/R710 & Zarco-Tejada et al. (2000) \\
\hline Simple Ratio Pigment Index (SRPI) & R430/R680 & Penuelas et al (1995) \\
\hline Normalized Phaeophytinization Index (NPQI) & (R415- R435)/(R415+R435) & Barnes et al. (1992) \\
\hline Photochemical Reflectance Index 1 (PRI1) & (R528- R567)/(R528+R567) & Gamon et al. (1992) \\
\hline Photochemical Reflectance Index 2 (PRI2) & (R531- R570)/(R531+R570) & Gamon et al. (1992) \\
\hline $\begin{array}{llll}\begin{array}{l}\text { Normalized } \\
\text { (NPCI) }\end{array} & \text { Pigment } & \text { Chlorophyll Index } \\
\end{array}$ & $(\mathrm{R} 680-\mathrm{R} 430) /(\mathrm{R} 680+\mathrm{R} 430)$ & Penuelas et al (1994) \\
\hline Carter Index 1 (Ctr1) & R695/R420 & Carter (1994) \\
\hline Carter Index 2 (Ctr2) & R695/R760 & Carter et al. (1996) \\
\hline Lichtenthaler Index 1 (LIC1) & $(\mathrm{R} 800-\mathrm{R} 680) /(\mathrm{R} 800+\mathrm{R} 680)$ & Lichtenthaler et al. (1996) \\
\hline Lichtenthaler Index 2 (LIC2) & R440/R690 & Lichtenthaler et al. (1996) \\
\hline Structure Intensive Pigment Index (SIPI) & $(\mathrm{R} 800-\mathrm{R} 450) /(\mathrm{R} 800+\mathrm{R} 650)$ & Penuelas et al. (1995) \\
\hline Vogelmann Index 1 (Vog1) & R740/R720 & Vogelmann et al. (1993) \\
\hline Vogelmann Index 2 (Vog2) & (R734-R747)/(R715+R726) & Vogelmann et al. (1993) \\
\hline Vogelmann Index 3 (Vog3) & (R734-R747)/(R715+R720) & Vogelmann et al. (1993) \\
\hline Gitelson and Merzlyak 1(GM1) & R750/R550 & $\begin{array}{l}\text { Gitelson and Merzlyak } \\
(1997)\end{array}$ \\
\hline Gitelson and Merzlyak 2(GM2) & R750/R700 & $\begin{array}{l}\text { Gitelson and Merzlyak } \\
(1997)\end{array}$ \\
\hline $\begin{array}{llll}\begin{array}{l}\text { Normalized } \\
\text { (NDVI) }\end{array} & \text { Difference } & \text { Vegetation } & \text { Index } \\
\end{array}$ & (R920-R696)/(R920+R696) & \\
\hline
\end{tabular}

Table 1. Formulas used for computation of various hyperspectral vegetation indices

\subsection{Correlation Analysis}

Correlation analysis was carried out between reflectance at specific bandwidths and hyperspectral indices with biophysical parameters like chlorophyll content and LAI of healthy and stressed plants.

\section{RESULTS AND DISCUSSIONS}

\subsection{Effect of disease on hyperspectral reflectance of crops}

The effect of disease on Brinjal can be clearly seen in Figure 3a, with green and fully turgid leaves and in Figure 3(b) there was a 
decrease in chlorophyll content and change in the internal leaf structure due to their shrivelling and curling.

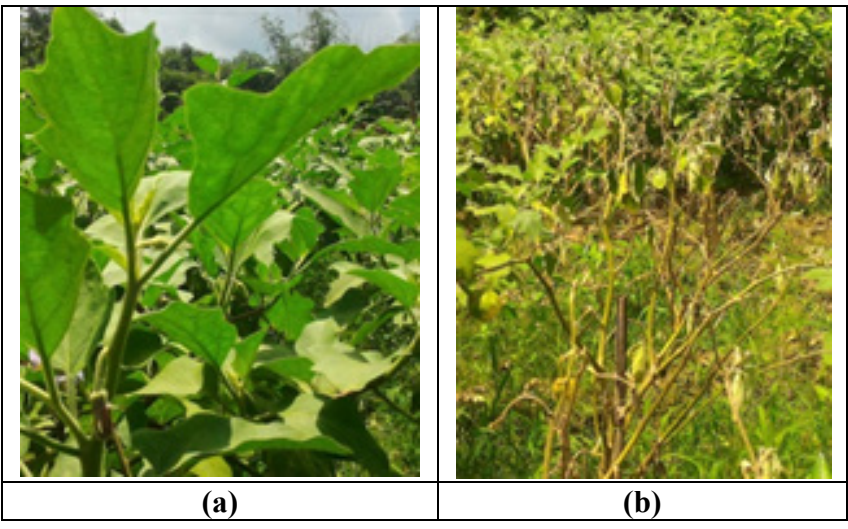

Figure 3(a) Healthy Brinjal plant, (b) Diseased Brinjal plant

The reflectance spectral curve (Figure 4) also shows a significant difference between diseased and healthy brinjal plants. In diseased and severly diseased brinjal there is a decrease in reflectance in the green region due to reduction in chlorophyll content and in near-infrared reflectance due to internal leaf damage. When a plant suffers from a stress factor such as pest or disease infestation, normal chlorophyll production diminishes, followed by a decrease in absorption and an increase in reflectance in the blue and red visible regions (Yang et al., 2010). Reflectance is also reduced in the NIR wavebands because as the mesophyll layer of the plants leaves is affected by the pathogen invasion, their internal reflective capacity diminishes, causing a reduction in reflection of NIR energy.

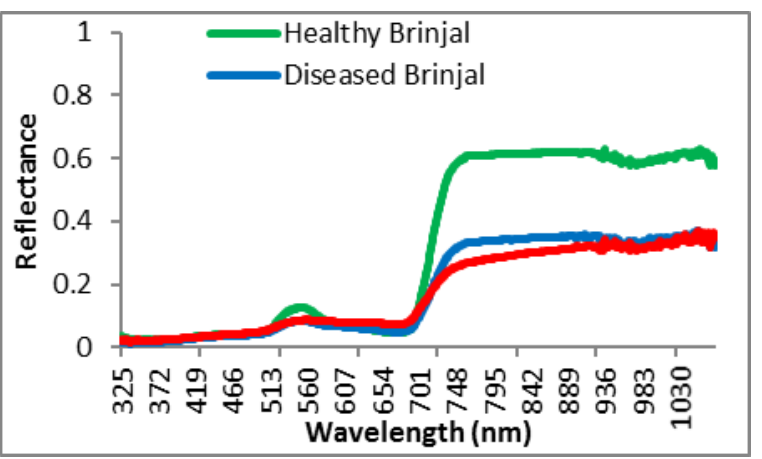

Figure 4 Comparison between spectra of normal and diseased Brinjal in Baruipur, West Bengal

\subsection{Correlation Results}

From the figures 5 and 6 , it has been observed that bandwidths of 528-531 nm, 550-570 nm, 710-760 nm, and single bands such as $800 \mathrm{~nm}$ and $920 \mathrm{~nm}$ shows strong positive correlation $\left(\mathrm{R}^{2}>0.9\right)$ with Chlorophyll Concentration Index (CCI) and Leaf Area Index (LAI).

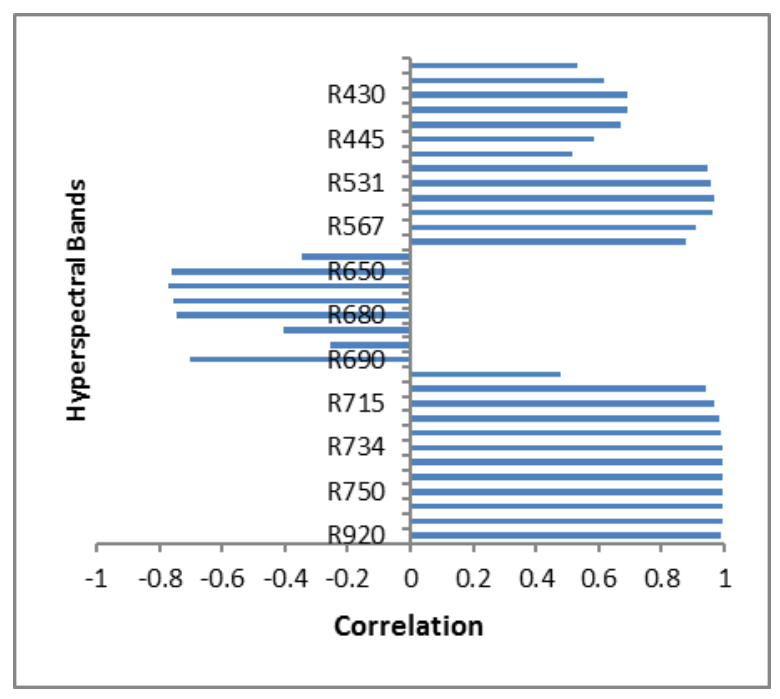

Figure 5. Correlation between chlorophyll content and Reflectance in narrow bands

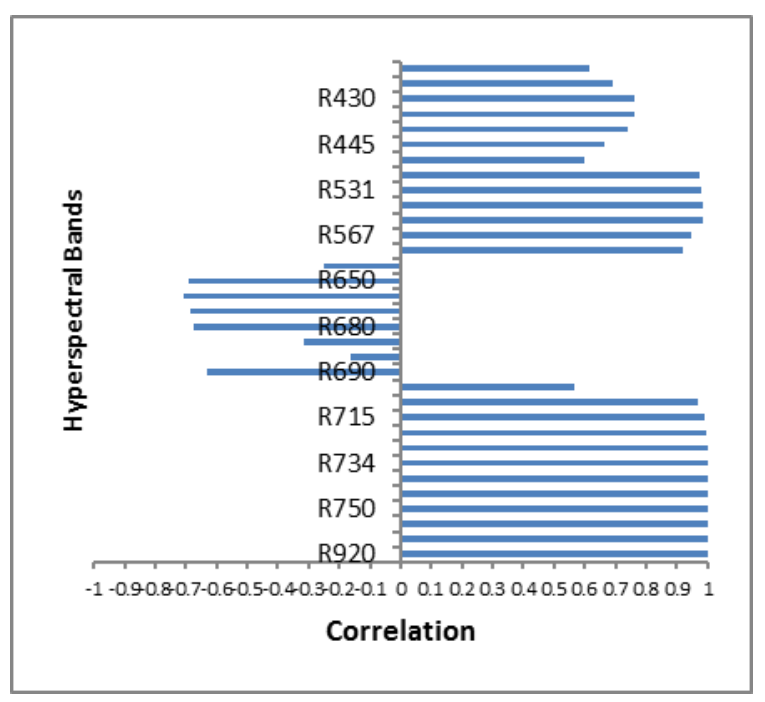

Figure 6. Correlation between Leaf Area Index and Reflectance in narrow bands

Indices viz. Greenness index, Modified Chlorophyll Absorption in Reflectance Index (MCARI), Transformed Chlorophyll Absorption in Reflectance Index (TCARI), Triangular Vegetation Index (TVI), Simple Ratio Pigment Index (SRPI), Photochemical Reflectance Index (PRI 2), Lichtenthaler Indices (LIC1, LIC2), Structure Intensive Pigment Index (SIPI) etc. were found to have strong positive correlation $\left(R^{2}>0.9\right)$ with above biophysical parameters.

\section{CONCLUSION}

Optical remote sensing techniques are well known for objective and reliable automated diagnosis and detection of plant diseases. Vegetations suffering from any kind of biotic stress show decrease in chlorophyll production and reduction of absorption in the red and blue visible region. The amount of reflectance in these regions on the other hand increases. The present study also confirms the same. 


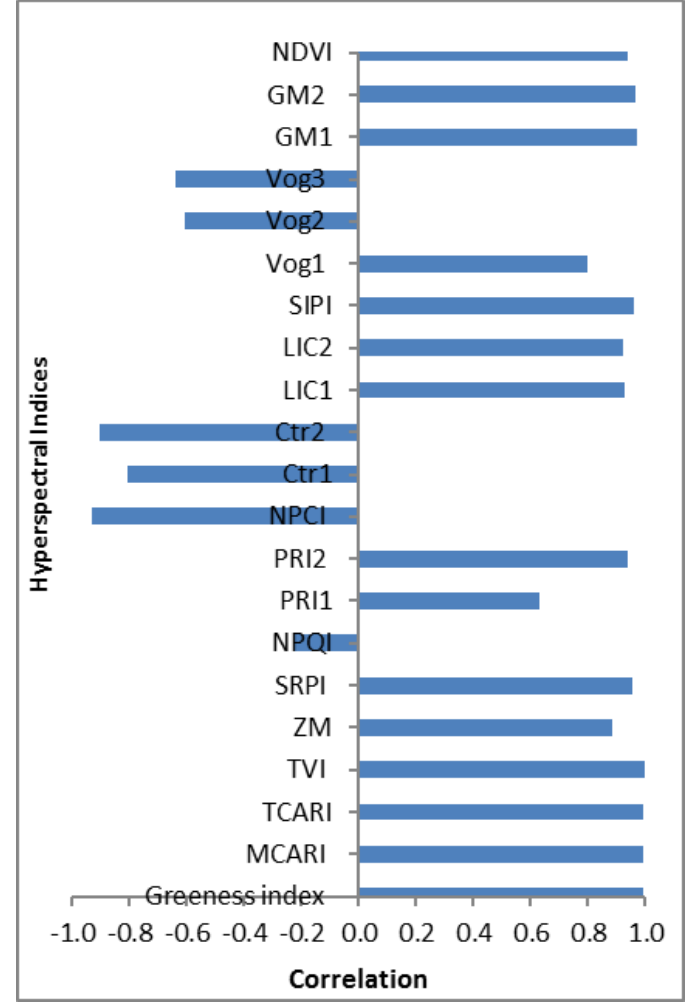

Figure 7 Correlation between chlorophyll content and Hyperspectral indices

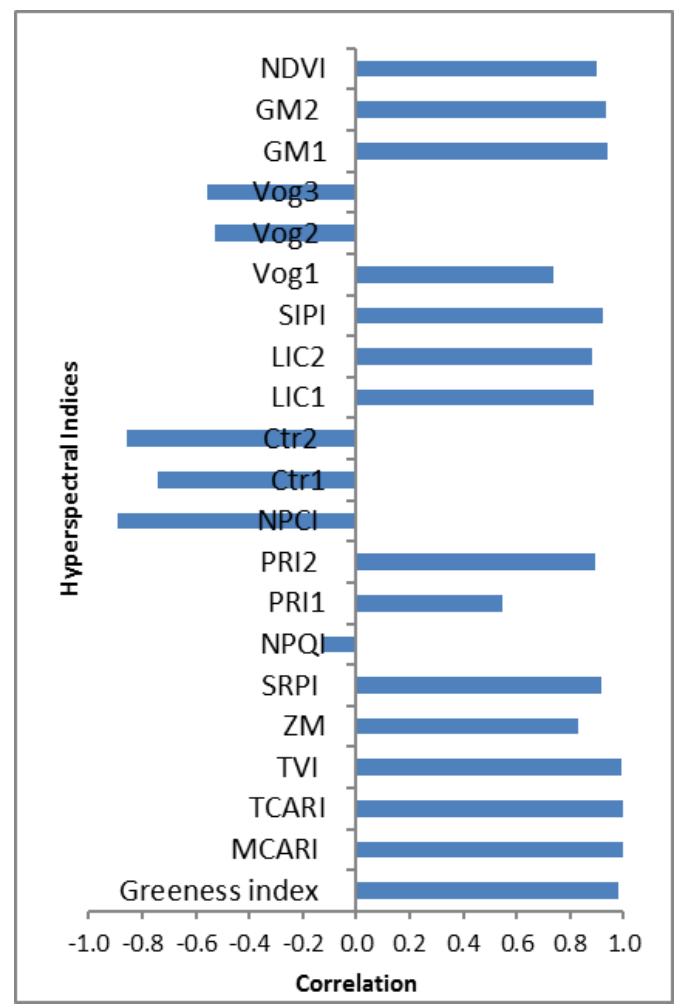

Figure 8 Correlation between Leaf Area Index and Hyperspectral indices

Bandwidths of $528-531 \mathrm{~nm}, 550-570 \mathrm{~nm}, 710-760 \mathrm{~nm}$, and single bands such as $800 \mathrm{~nm}$ and $920 \mathrm{~nm}$ and indices viz. Greenness index, Modified Chlorophyll Absorption in Reflectance Index (MCARI), Transformed Chlorophyll
Absorption in Reflectance Index (TCARI), Triangular Vegetation Index (TVI), Simple Ratio Pigment Index (SRPI), Photochemical Reflectance Index (PRI 2), Lichtenthaler Indices (LIC1, LIC2), Structure Intensive Pigment Index (SIPI) etc. were found to have strong positive correlation $\left(\mathrm{R}^{2}>0.9\right)$ with biophysical parameters. These specific bandwidths and indices can be helpful in regional biophysical parameter estimation through corresponding satellite derived band data and early detection of crop stress, crop growth and disease monitoring.

\section{ACKNOWLEDGEMENT}

The following study was carried under the CHAMAN (Coordinated Horticulture Assessment and Management using geoiNformatics) project under Mission for Integrated Development of Horticulture (MIDH) of Ministry of Agriculture, cooperation and Farmer's Welfare. Authors are thankful to Secretary, DAC\&FW, Additional Secretary (Horticulture), Joint Secretary (MIDH) and Adviser (Horticulture Statistics) for their constant encouragement and keen interest in the study. Authors thank officials of State Horticulture Department of West Bengal for their cooperation and logistic support for carrying out ground truth.

\section{REFERENCES}

Apan, A., B. Datt., and R. Kelly., 2005. Detection of Pests and Disease in Vegetable Crops Using Hyperspectral Sensing: A Comparison of Data for Different Symptoms. Proceedings of SSC 2005 Spatial Intelligence and Innovation, pp. 10-18.

Apogee Instruments Inc.,2013. Owner's Manual Chlorophyll Concentration Meter, Model MC 110, Utah,USA.

ASD, Inc., 2010. FieldSpec ${ }^{\circledR}$ HandHeld $2^{\mathrm{TM}}$ Spectroradiometer User's Manual. Boulder, CO, USA.

Blackburn, G., 1998a. Spectral indices for estimating photosynthetic pigment concentrations: a test using senescent tree leaves. International Journal of Remote Sensing (4), pp. 657-675.

Blackburn, G., 1998b. Quantifying Chlorophylls and Carotenoids at Leaf and Canopy Scales: An Evaluation of Some Hyperspectral Approaches. Remote Sensing of the Environment (66), pp. 273-285.

Blakeman, R. H., 1990. The identification of crop disease and stress by aerial photography. In: Application of Remote Sensing in Agriculture, edited by M. D. Steven and J. A. Clark, Butterworths, London, UK, pp. 229-254.

Blazquez, C. H., and Edwards, G. J., 1983. Infrared color photography and spectral reflectance of tomato and potato diseases. Journal of Applied Photographic Engineering (9), pp. $33-37$.

Chapelle, E. W., and Kim, M. S., 1992. Ratio analysis of reflectance spectra (RARS): an algorithm for the remote estimation of concentration of chlorophyll $\mathrm{a}$, chlorophyll $\mathrm{b}$ and 
carotenoids in soybean leaves. Remote Sensing of Environment (18), pp. 255-267.

Chatterjee, S., Mukherjee, N., Khatua, D.C., 1997. Status of Bacterial wilt Disease in West Bengal. J. Interacad (1), pp.9799.

Choudhary, B., Gaur, K., 2009. The development and regulation of bt-brinjal in India (Eggplant/Aubergine). ISAAA Brief No.38. ISAAA: Ithaca, NY.

CID Bioscience Inc., 2014. Plant Canopy Imager, CI-110 Instruction Manual, Camas,WA,USA.

Das, CR., Chattopadhyay, S.B., 1955. Bacterial wilt of egg plant. Indian Phytopath (8), pp.130-135.

Fitzgerald, G. J., Maas, S. J., and Detar, W. R., 2004. Spider mite detection and canopy component mapping in cotton using hyperspectral imagery and spectral mixture analysis. Precision Agriculture (5), pp. 275-289.

Gitelson, A., G., Keydan, and M. Merzlyak., 2006. Three-band model for noninvasive estimation of chlorophyll, carotenoids, and anthocyanin contents in higher plant leaves. Geophysical Research Letters (33), pp. 1-5.

Gitelson, A., Y. Zur., O. Chivkunova., and M. Merzlyak., 2002. Assessing Carotenoid Content in Plant Leaves with Reflectance. Photochemistry and Photobiology (3), pp. 272-281.

Guyot, G., 1990. Optical properties of vegetation canopies. In: Applications of Remote Sensing in Agriculture, edited by M. D. Steven and J. Clark, Butterworths, London UK, pp. 19-43.

Haboudane, D., N. Tremblay., J. Miller., and P. Vigneault., 2008. Remote Estimation of Crop Chlorophyll Content Using Spectral Indices Derived From Hyperspectral Data. IEEE Transactions on Geoscience and Remote Sensing (2), pp. 423437.

Hatfield, J. L. and Pinter, P. J., Jr. 1993. Remote sensing for crop protection. Crop Protection (12), pp. 403-414.

Jacquemoud, S., and S. Ustin., 2001. Leaf Optical Properties: A State of the Art. 8th International Symposium of Physical Measurements \& Signatures in Remote Sensing, CNES, pp. 223-232.

Jones, H., and R. Vaughan., 2010. Remote Sensing of Vegetation (1st ed.). Oxford: Oxford University Press.

Kumar, J., Vashisth, A., Sehgal, V. K. and Gupta, V. K., 2010. Identification of aphid infestation in mustard by hyperspectral remote sensing. Journal of Agricultural Physics (10), 53-60.

Kurschner, E., Walter, H., and Koch, W., 1984. Measurements of spectral reflectance of leaves as a method for assessing the infestation with powdery mildew. Journal of Plant Disease Protection (91), pp. 71-80.
Lillesand, T. M., and Kiefer, R. W., 1994. Remote Sensing and Image Interpretation. 3rd edn, John Wiley \& Sons, New York, USA.

Mondal, B., Bhattacharya, I., Khatua, D.C., 2014. Incidence of bacterial wilt disease in West Bengal, India. Academia Journal of Agricultural Research , 2(6), pp.139-146.

Mondal, B., Bhattacharya, R., Ranjan, R.K., Khatua, D.C., 2004b. Bacterial wilt of horticultural plants in West Bengal and its chemical control. Green Tech (6), pp. 70-74.

Ray, S. S., Das, G., Singh, J. P. and Panigrahy, S., 2006. Evaluation of hyperspectral indices for LAI estimation and discrimination of potato crop under different irrigation treatments. International Journal of Remote Sensing (27), pp. 5373-5387.

Ray, S. S., Jain, N., Arora, R. K.., Chavan, S., and Panigrahy, S.,2011. Utility of hyperspectral data for potato late blight disease detection. J. Indian Society Remote Sensing ,39(2), pp. 161-169.

Sahoo, R.N., Ray, S.S., Manjunath, K.R., 2015. Hyperspectral remote sensing of agriculture.Current Science. 108 (5),pp.848859

Samaddar, K.R., Chakraborty, M., Kanjilal, S., 1998. Identification of the race of Pseudomonas solanacearum causing wilt of solanaceaus vegetables in West Bengal and its survival. J. Mycopathol. Res. 36 (2), pp.51-58.

Serrano, L., J. Penuelas, and S. Ustin., 2002. Remote sensing of nitrogen and lignin in Mediterranean vegetation from AVIRIS data: Decomposing biochemical from structural signals. Remote Sensing of the Environment, (81), pp. 355-364.

Shibayama, M., Takahashi, W., Morinaga, S., and Akiyama, T., 1993. Canopy water deficit detection in paddy rice using a high resolution field spectrometer. Remote Sensing of Environment (45), pp. 117-126.

Thomas, J. R., and Oerther, G. F., 1972. Estimating nitrogen content of sweet pepper leaves by reflectance measurements. Agronomy Journal (64), pp. 11-13.

Toler, R. W., Smith, B. D., and Harlan, J. C., 1981. Use of aerial color infrared photography to evaluate crop disease. Plant Disease (65), pp. 24-31.

Yang, F., J. Li., X. Gan., Y. Qian., X. Wu., and Q. Yang., 2010. Assessing nutritional status of Festuca arundinacea by monitoring photosynthetic pigments from hyperspectral data. Computers and Electronics in Agriculture (70), pp. 52-59.

Zhang, M., Liu, X., and Oneill, M., 2002. Spectral Discrimination of Phytophthora infestans infection on tomatoes based on principal component and cluster analyses. International Journal of Remote Sensing 23(6), pp. 1095-1107. 